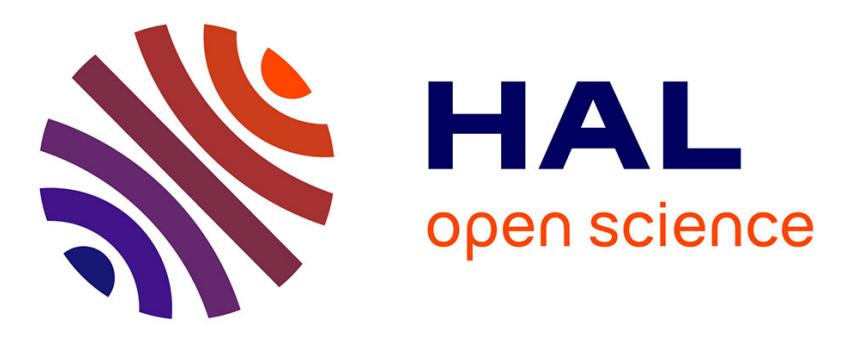

\title{
A New Species of the Graphium (Pazala) mandarinus Group from Central Vietnam (Lepidoptera: Papilionidae)
}

Shao-Ji Hu, Fabien Condamine, Alexander Monastyrskii, Adam Cotton

\section{- To cite this version:}

Shao-Ji Hu, Fabien Condamine, Alexander Monastyrskii, Adam Cotton. A New Species of the Graphium (Pazala) mandarinus Group from Central Vietnam (Lepidoptera: Papilionidae). Zootaxa, 2019, 4554 (1), pp.286-300. 10.11646/zootaxa.4554.1.10 . hal-02323693

\section{HAL Id: hal-02323693 \\ https://hal.science/hal-02323693}

Submitted on 4 Dec 2020

HAL is a multi-disciplinary open access archive for the deposit and dissemination of scientific research documents, whether they are published or not. The documents may come from teaching and research institutions in France or abroad, or from public or private research centers.
L'archive ouverte pluridisciplinaire HAL, est destinée au dépôt et à la diffusion de documents scientifiques de niveau recherche, publiés ou non, émanant des établissements d'enseignement et de recherche français ou étrangers, des laboratoires publics ou privés.

\section{(c)(1)}

Distributed under a Creative Commons Attribution| 4.0 International License 
https://doi.org/10.11646/zootaxa.4554.1.10

http://zoobank.org/urn:lsid:zoobank.org:pub:1E207D13-8863-4272-8C52-8C6E61F890D6

\title{
A New Species of the Graphium (Pazala) mandarinus Group from Central Vietnam (Lepidoptera: Papilionidae)
}

\author{
SHAO-JI HU ${ }^{1,2}$, FABIEN L. CONDAMINE ${ }^{3}$, ALEXANDER L. MONASTYRSKII ${ }^{4}$ \& ADAM M. COTTON AD $^{5,6}$ \\ ${ }^{\prime}$ Yunnan Key Laboratory of International Rivers and Transboundary Eco-security, Yunnan University, Kunming, 650500, China \\ ${ }^{2}$ Institute of International Rivers and Eco-security, Yunnan University, Kunming, 650500, China \\ ${ }^{3}$ CNRS, UMR 5554 Institut des Sciences de l'Evolution de Montpellier, Université de Montpellier, Place Eugène Bataillon 34095 \\ Montpellier, France \\ ${ }^{4}$ Fauna \& Flora International, Vietnam Programme, Hanoi, Vietnam \\ ${ }^{5} 86 / 2$ Moo 5, Tambon Nong Kwai, Hang Dong, Chiang Mai, Thailand \\ ${ }^{6}$ Corresponding author. E-mail: adamcot@cscoms.com
}

\begin{abstract}
The Graphium (Pazala) mandarinus group was recently defined and the status of taxa as well as the number of species was revised. We report here the discovery of a new species from Kon Tum plateau of the Truong Son (Annamite) Range of Central Vietnam, which we describe based on morphological and molecular evidence. Molecular phylogeny shows that the new taxon, G. (P.) wenlingae Hu, Cotton \& Monastyrskii sp. nov., is sister to G. (P.) daiyuanae Hu, Zhang \& Cotton, 2018 plus $G$. (P.) confucius Hu, Duan \& Cotton, 2018. Molecular dating analysis further suggests that this new species diverged from its sister clade in the Pliocene ( $\sim 3.5$ million years ago). The new taxon constitutes the eighth and southernmost species of the mandarinus group.
\end{abstract}

Key words: Pazala, mandarinus-group, new species, Vietnam, Leptocircini

\section{Introduction}

The Graphium (Pazala) mandarinus group was defined by $\mathrm{Hu}$ et al. (2018) with the discovery of five cryptic species among the two originally recognised species (Racheli \& Cotton 2009). The main distinguishing character of the mandarinus group is the two discal black bands on the hindwing underside twisted into an " 8 "-shaped pattern, resembling a pair of glasses in appearance (Hu et al. 2018).

Shortly after the publication of the mandarinus group work (Hu et al. 2018) the authors of the present study received three specimens of Pazala swallowtails from two localities of Central Vietnam. Two specimens caught in 1998 were found in the collection of the Vietnam Forest Museum (VFM), Hanoi, bringing the total known number of specimens to $3 \hat{\delta} \widehat{\jmath}$ and 2 웅. The external appearances of these specimens are similar to G. (P.) daiyuanae Hu, Zhang \& Cotton, 2018, while several characters exhibit stable differences. After a careful examination of both external morphological characters and structure of male and female genitalia, along with analyses of molecular phylogeny and genetic distances, the specimens from Central Vietnam are believed to be a distinct species and are described herein.

\section{Materials and methods}

Taxon sampling. Five specimens of the new taxon collected from Central Vietnam were examined in the present study. All samples were used for morphological comparison, while only three freshly collected samples, from 2017 and 2018, were used for molecular analyses. Specimens listed in Appendix 1 of Hu et al. (2018) and their DNA data are also integrated in this study.

Morphological comparison. Specimens were spread for examination, with the scent scales on their hindwings exposed. 
Spread specimens were photographed using a Fujifilm S8600 digital camera (Fujifilm, Japan) with medium grey background. Photos were adjusted using Adobe Photoshop CS (Adobe, USA). Diagnostic characters of the new taxa were also denoted using Adobe Photoshop CS. For comparison between taxa, the lengths of forewing were measured to $0.5 \mathrm{~mm}$ precision. Average lengths and the standard deviations were also calculated when $n \geq 3$.

To observe the male and female genitalia, the abdomen was taken from the specimen and placed into a $1.5 \mathrm{~mL}$ microcentrifuge tube, and $1 \mathrm{~mL}$ water was added to the abdomen to rehydrate the tissue at $50{ }^{\circ} \mathrm{C}$ for $30 \mathrm{~min}$, then 1 $\mathrm{mL} 10 \%$ sodium hydroxide solution was used to digest soft tissue at $70{ }^{\circ} \mathrm{C}$ for $1 \mathrm{~h}$. The treated abdomen was neutralised with $2 \%$ acetic acid and then dissected in a water-filled Petri dish under the stereoscope to remove residual tissues, scales, and hair. The genitalia were then transferred to $80 \%$ glycerol for $12 \mathrm{~h}$ to render them transparent. Photographs were taken with a Nikon DMX1200 digital camera (Nikon, Japan) mounted on a Nikon SMZ1500 stereoscope (Nikon, Japan) and automatically stacked using Helicon Focus 3.2 (Helicon Software, USA). The distance between socii of male genitalia is a useful morphometric character helpful to distinguish species (Koiwaya 1993); therefore this distance was measured to $0.2 \mathrm{~mm}$ precision for all dissected male genitalia. After observation and photography, all parts of the genitalia were fixed on a glue card and pinned with the specimen.

Terminology of genitalia follows Hu et al. (2018) and wing venation is as per Smith \& Vane-Wright (2001).

Molecular work. For the three fresh specimens, one or two legs (except forelegs) on the same side were extracted, homogenised in protease buffer containing $100 \mu \mathrm{L} \mathrm{STE}(10 \mathrm{mmol} / \mathrm{L}$ Tris-HCl, $1 \mathrm{mmol} / \mathrm{L}$ EDTA, 100 $\mathrm{mmol} / \mathrm{L} \mathrm{NaCl}, \mathrm{pH}=8.0)$ and $2 \mu \mathrm{L}$ Proteinase $\mathrm{K}(20 \mathrm{mg} / \mathrm{mL}$ ) (O'Neill et al. 1992). Homogenised samples were treated at $37{ }^{\circ} \mathrm{C}$ incubation for $15 \mathrm{~min}$ to rehydrate the tissue and then at $95{ }^{\circ} \mathrm{C}$ incubation for $10 \mathrm{~min}$ to lyse the tissue. The supernatant was recovered through centrifugation at $6,000 \mathrm{~g}$ and used directly as DNA template in polymerase chain reactions (PCR).

The PCR reaction was executed in a $25 \mu \mathrm{L}$ system by using TaKaRa Ex Taq Kit (TaKaRa Biotechnology Co., Ltd., Dalian, China) that contained $2.5 \mu \mathrm{L}$ of $10 \times$ PCR buffer, $2.0 \mu \mathrm{L}$ of $\mathrm{MgCl}_{2}(25 \mathrm{mmol} / \mathrm{L}), 2.0 \mu \mathrm{L}$ of dNTP mixture $(2.5 \mathrm{mmol} / \mathrm{L}$ each), $0.25 \mu \mathrm{L}$ of Taq DNA polymerase $(5 \mathrm{U} / \mu \mathrm{L})$, and $0.5 \mu \mathrm{L}$ of each of forward and reverse primers $(20 \mu \mathrm{mol} / \mathrm{L})$. We sequenced the mitochondrial barcode COI (cytochrome $c$ oxidase subunit I, coxl) with the following primers LCO1490 (5'- GGT CAA CAA ATC ATA AAG ATA TTG G-3') and HCO2198 (5'- TAA ACT TCA GGG TGA CCA AAA AAT CA-3') (Folmer et al. 1994). The thermal profile of PCR consisted of an initial denaturation at $95{ }^{\circ} \mathrm{C}$ for $3 \mathrm{~min} ; 30$ cycles of denaturation at $94{ }^{\circ} \mathrm{C}$ for $1 \mathrm{~min}$, annealing at $50{ }^{\circ} \mathrm{C}$ for $1 \mathrm{~min}$, and elongation at $72{ }^{\circ} \mathrm{C}$ for $1 \mathrm{~min}$; then a final elongation at $72{ }^{\circ} \mathrm{C}$ for $5 \mathrm{~min}$. Sequences were obtained by using an ABI Prism 3730 sequencer (Applied Biosystems, California, USA).

Phylogenetic analyses. Raw sequences were proofread and aligned using Clustal W (Thompson et al. 1994) in BioEdit 7.0.9 (Hall 1999), and any sequence containing double peaks in the chromatograms was strictly excluded. The product sequences were checked by BLAST against the genomic references and nucleotide collection in NCBI. Amino acid translation was realised with the invertebrate mitochondrial criterion in MEGA 6.0 (Tamura et al. 2013) to detect possible Numts (nuclear copies of mtDNA fragments). A search for nonsynonymous mutations, in-frame stop codons, and indels was carried out to further minimise the existence of cryptic Numts (Song et al. 2008; Bertheau et al. 2011). Sequences used in the present study, including those derived from Hu et al. (2018), were listed in Table 1.

The phylogeny was reconstructed using the Bayesian Inference (BI) method as implemented in MrBayes 3.2.6 (Ronquist et al. 2012), with the most appropriate partition scheme recovered by PartitionFinder 2.1.1 (Lanfear et al. 2017) using the unlinked branch lengths and the greedy algorithm. We used the partitioning scheme and amongsite rate variation suggested by PartitionFinder but instead of selecting one substitution model a priori, we used reversible-jump Markov Chain Monte Carlo (rj-MCMC) to allow sampling across the entire substitution rate model space (Huelsenbeck et al. 2004). BI analyses consisted of three independent runs, each with eight rj-MCMC running for 10 million generations (sampled every $1000^{\text {th }}$ generation) to calculate the clade posterior probabilities (PP).

Maximum likelihood analyses were also carried out using IQ-TREE 1.6.8 (Nguyen et al. 2015). The dataset was partitioned as determined by PartitionFinder. The corresponding substitution models were searched using the Auto function on the IQ-TREE based on the corrected Akaike information criterion. We performed 1000 ultrafast bootstrap replicates (Minh et al. 2013) to investigate nodal support across the topology considering bootstrap values $(\mathrm{BV}) \geq 95$ as strongly supported.

As in Hu et al. (2018), we used an individual of Iphiclides podalirius (Linnaeus, 1758) and of Lamproptera 
meges (Zinken, 1831), because we found that tree topology and node support were improved when using outgroup species that branched before Pazala. We reconstructed the phylogeny for a dataset containing the currently recognised species of Pazala (sensu Hu et al. 2018) in an attempt to obtain an overall phylogenetic framework for the subgenus and to produce phylogenetic relationships among the focal taxon in the present study $(G$. wenlingae sp. nov.).

Phyletic properties of each taxon in the mandarinus group were assessed using an online tool, Monophylizer (Mutanen et al. 2016; http://monophylizer.naturalis.nl/). Taxa identified as monophyletic were treated as good species or subspecies, while those identified as paraphyletic (the terms 'entangled' and 'tanglees' described by Mutanen et al. 2016 were adopted to refer to such taxa in this study) were further analysed using morphological characters and geographical ranges.

Molecular dating. To estimate divergence times and infer their $95 \%$ credibility intervals (CI), we performed Bayesian relaxed-clock analyses using MrBayes. For these analyses, we relied on the partitioning scheme and all the MrBayes settings as determined above. Dating analyses were realized with three independent runs for 20 million generations with sampling tree every 2,000 generations. We used the autocorrelated clock model of Thorne \& Kishino (2002, noted TK02 in MrBayes) for two reasons. First, the autocorrelated model is more appropriate for our dataset because the rate along a given branch is more similar to its parent branch than a branch chosen at random, though autocorrelation models differ in the degree to which they restrict rate variation between parent and daughter branches (Thorne et al. 1998; Thorne \& Kishino 2002). Second, Lepage et al. (2007) and Rehm et al. (2011) showed that the autocorrelated clock model generally offers the best fit, as compared to the uncorrelated model and a strict molecular clock model.

Calibration priors are based on the time-calibrated tree of Papilionidae (Condamine et al. 2012). We set four secondary calibrations using a (conservative) uniform prior with bounded by the minimum and maximum ages of the $95 \% \mathrm{CI}$ of the divergence times (a normal prior is not recommended, Schenk 2016). We could not use fossils in this study because the three fossils do not belong to the subfamily Papilioninae (Condamine et al. 2012). We calibrated the following nodes: (i) the root of the tree (crown of Leptocircini) set between 27.6 and $43.4 \mathrm{Ma}$; (ii) the crown between Iphiclides and Lamproptera set between 20.8 and 35.5 Ma; (iii) the crown of the genus Graphium set between 21.2 and 35.7 Ma; and (iv) the crown of the subgenus Graphium set between 14.4 and 29.7 Ma.

For all Bayesian runs (phylogenies and dating), convergence was ensured by checking average deviation of split frequencies (ADSF), potential scale reduction factor (PSRF) values, effective sample size (ESS) of all parameters, and by plotting log-likelihood of samples against number of generations in Tracer 1.6. To reach good convergence, the runs must have values of ADSF approaching zero, PSRF close to 1.00 and ESS above 200. Bayesian consensus trees were obtained using the $25 \%$ burn-in criterion (Ronquist et al. 2012), and the remaining samples were used to generate a $50 \%$ majority rule consensus tree.

All phylogenetic and dating analyses were performed on the computer cluster CIPRES Science Gateway (Miller et al. 2015), using BEAGLE (Ayres et al. 2012) with default parameters.

\section{Results}

Molecular analyses. We obtained 658 base pairs of the mitochondrial gene COI for three specimens of $G$. wenlingae sp. nov., which were added to the data available for the mandarinus group (Hu et al. 2018). The partitioning analyses indicated that the COI gene should be divided into three partitions corresponding to each codon position. PartitionFinder further suggested that GTR model with invariable site and Gamma distribution should be applied, but we used the reversible-jump MCMC to explore a broader range of substitution models during the analyses. The Bayesian analyses showed that the new taxon, $G$. (P.) wenlingae sp. nov., is sister to $G$. (P.) daiyuanae $+G$. (P.) confucius (Figure 1). Topology and monophyly of other clades of the updated Bayesian tree of the mandarinus group remains the same as that reported by $\mathrm{Hu}$ et al. (2018), except G. (P.) mandarinus stilwelli was entangled with both $G$. (P.) mandarinus fangana and G. (P.) mandarinus mandarinus (Figure 1; Table 2).

The Bayesian molecular dating analysis estimated very similar divergence times as those reported in $\mathrm{Hu}$ et al. (2018). The entire mandarinus group split from its ancestor at $17.94 \mathrm{Ma}$ (95\% CI: 11.21-25.1 Ma) (Figure 2). Three clades, G. (P.) wenlingae sp. nov. + G. (P.) daiyuanae $+G$. (P.) confucius, G. (P.) sichuanica + G. $(P$. hoeneanus, and the entire G. (P.) mandarinus clade formed a trichotomy in the dating tree, with a node age at 5.73 Ma (95\% CI: 2.65-10.15 Ma) (Figure 2). The new taxon, G. (P.) wenlingae sp. nov., split from its ancestor at 3.54 Ma (95 CI: 1.31-7.11 Ma). 


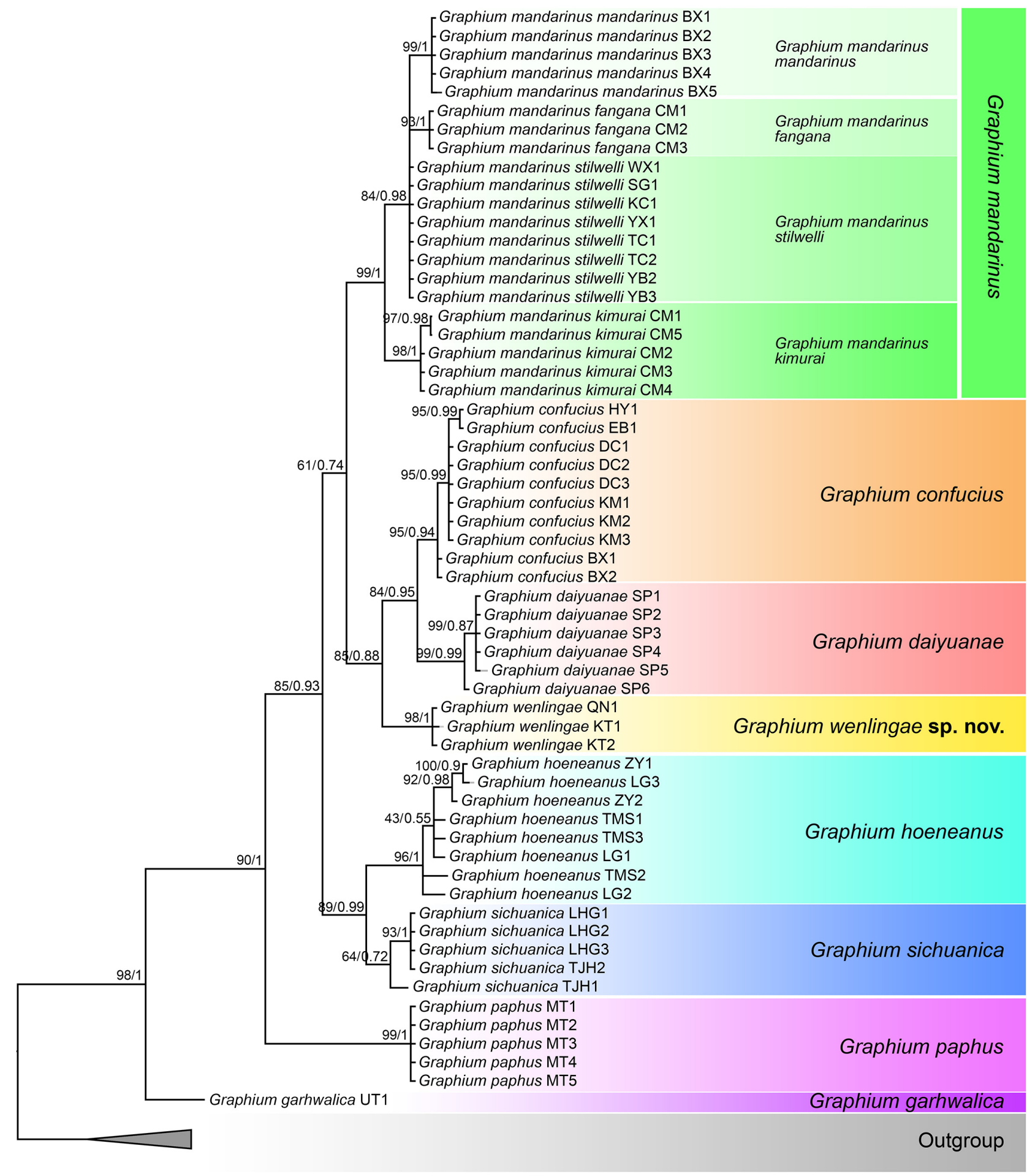

0.02

FIGURE 1. Bayesian phylogenetic tree of Graphium (Pazala) mandarinus group, with outgroups collapsed. Coloured rectangles delineate the species and subspecies, values at nodes indicate the bootstrap value/posterior probability.

Kimura 2-parameter (K2P) genetic distance (Table 3) computed between $G$. (P.) wenlingae sp. nov. and $G$. (P.) daiyuanae was $2.38 \%$, and that between $G$. (P.) wenlingae sp. nov. and $G$. $(P$.) confucius was $2.24 \%$, both greater than the K2P distance between $G$. $(P$.$) daiyuanae and G. (P$.$) confucius (1.71 \%)$. The K2P distances between $G .(P$. wenlingae sp. nov. and other morphologically similar taxa, namely $G$. (P.) mandarinus kimurai, $G$. $(P$.) mandarinus fangana, and G. (P.) mandarinus stilwelli, all exceeded 3\%. It is also noticeable that the K2P distance between $G$. $(P$.) wenlingae sp. nov. and $G$. (P.) sichuanica was greater than that between $G$. $(P$.) wenlingae sp. nov. and $G$. $(P$.) hoeneanus. 
TABLE 1. Specimens used in molecular analysis with GenBank accession numbers, accession numbers shared between samples with the same coxl sequence.

\begin{tabular}{|c|c|c|}
\hline Taxon (sample code) & Locality & Accession No. \\
\hline$\overline{G .(P .) \text { garhwalica }(\mathrm{UT1})}$ & Joshimath, Uttaranchal, India & MG197758 \\
\hline G. (P.) paphus (MT1-5) & Metok, Tibet, China & MG197757 \\
\hline G. (P.) sichuanica (LHG1-3) & Laohegou, Sichuan, China & MG197767 \\
\hline G. $($ P.) sichuanica $(\mathrm{TJH} 1)$ & Tangjiahe, Sichuan, China & MG197768 \\
\hline G. $(P$.$) sichuanica (\mathrm{TJH} 2)$ & Tangjiahe, Sichuan, China & MG197767 \\
\hline G. (P.) hoeneanus (ZY1) & Ziyuan, Guangxi, China & MG197762 \\
\hline G. (P.) hoeneanus (ZY2) & Ziyuan, Guangxi, China & MG197763 \\
\hline G. (P.) hoeneanus (LG1) & Lingui, Guangxi, China & MG197764 \\
\hline G. (P.) hoeneanus (LG2) & Lingui, Guangxi, China & MG197765 \\
\hline G. (P.) hoeneanus (LG3) & Lingui, Guangxi, China & MG197766 \\
\hline G. (P.) hoeneanus (TMS1) & W. Tianmu Shan, Zhejiang, China & MG197759 \\
\hline G. (P.) hoeneanus (TMS2) & W. Tianmu Shan, Zhejiang, China & MG197760 \\
\hline G. (P.) hoeneanus (TMS3) & W. Tianmu Shan, Zhejiang, China & MG197761 \\
\hline G. $(P$.$) wenlingae sp. nov. (KT1)$ & Ngoc Linh, Kon Tum, Vietnam & MH892413 \\
\hline G. $(P$.$) wenlingae sp. nov. (KT2)$ & Ngoc Linh, Kon Tum, Vietnam & MH892412 \\
\hline G. $(P$.$) wenlingae sp. nov. (QN1)$ & Tay Giang, Quang Nam, Vietnam & MH892412 \\
\hline G. (P.) daiyuanae (SP1-4) & Sapa, Lao Cai, Vietnam & MG197773 \\
\hline G. (P.) daiyuanae (SP5) & Sapa, Lao Cai, Vietnam & MG197774 \\
\hline G. (P.) daiyuanae (SP6) & Sapa, Lao Cai, Vietnam & MG197775 \\
\hline G. $(P$.$) confucius (HY1)$ & Hanyuan, Sichuan, China & MG197770 \\
\hline G. $(P$.$) confucius (EB1)$ & Ebian, Sichuan, China & MG197770 \\
\hline G. $(P$.$) confucius (\mathrm{BX} 1-2)$ & Baoxing, Sichuan, China & MG197769 \\
\hline G. $(P$.$) confucius (DC1, DC3)$ & Dongchuan, Yunnan, China & MG197771 \\
\hline G. $(P$.$) confucius (\mathrm{DC} 2)$ & Dongchuan, Yunnan, China & MG197772 \\
\hline G. (P.) confucius (KM1-3) & Kunming, Yunnan, China & MG197771 \\
\hline G. (P.) mandarinus kimurai (CM1) & Doi Inthanon, Chiang Mai, Thailand & MG197752 \\
\hline G. (P.) mandarinus kimurai (CM2-4) & Doi Inthanon, Chiang Mai, Thailand & MG197753 \\
\hline G. (P.) mandarinus kimurai (CM5) & Doi Inthanon, Chiang Mai, Thailand & MG197754 \\
\hline G. (P.) mandarinus fangana (CM1-3) & Doi Phu Meun, Chiang Mai, Thailand & MG197751 \\
\hline G. (P.) mandarinus stilwelli (WX1) & Weixi, Yunnan, China & MG197755 \\
\hline G. (P.) mandarinus stilwelli (YX1) & Yunxian, Yunnan, China & MG197755 \\
\hline G. (P.) mandarinus stilwelli (TC1-2) & Tengchong, Yunnan, China & MG197755 \\
\hline G. (P.) mandarinus stilwelli (YB1-2) & Yangbi, Yunnan, China & MG197755 \\
\hline G. (P.) mandarinus stilwelli (SG1) & Tarung Hka River, Sagaing, Myanmar & MG197755 \\
\hline G. (P.) mandarinus stilwelli $(\mathrm{KC} 1)$ & Chudu Razi Hills, Kachin, Maynmar & MG197755 \\
\hline G. (P.) mandarinus mandarinus (BX1-4) & Baoxing, Sichuan, China & MG197749 \\
\hline G. (P.) mandarinus mandarinus (BX5) & Baoxing, Sichuan, China & MG197750 \\
\hline
\end{tabular}

\section{Graphium (Pazala) wenlingae Hu, Cotton \& Monastyrskii sp. nov.} (Figure 3)

Pazala glycerion: Monastyrskii \& Devyatkin, 2000: 473. C. Vietnam (Ngoc Linh) Graphium (Pazala) mandarinus [partim]: Monastyrskii \& Devyatkin, 2003: 12. C. Vietnam (to Lam Dong). 
Description: Male: Forewing length: $29.5-32.0 \mathrm{~mm}$ (mean $=31.2 \pm 1.44 \mathrm{~mm}, n=3$ ). Forewing triangulate, broad, apex not produced, termen slightly concave in the medium portion. Forewing upperside: white, the upper and outer $1 / 3$ (mostly the discocellular, the subterminal, and the terminal areas) hyaline and glossy; 10 black bands lined from the humeral to the termen, among which the $1^{\text {st }}$ to the $6^{\text {th }}$ almost run parallel; the $1^{\text {st }}$ and the $2^{\text {nd }}$ bands reach the tornal margin, the $3^{\text {rd }}$ to the $5^{\text {th }}$ bands extend beyond the discal cell and abut up the base of veins $\mathrm{CuA}_{2}, \mathrm{CuA}_{1}$, and $\mathrm{M}_{3}$, the $6^{\text {th }}$ band at the end of cell, often connected with the $5^{\text {th }}$ band by a transverse black fine line, the $7^{\text {th }}$ band joins the $8^{\text {th }}$ band just at vein $\mathrm{M}_{2}$, extends to the tornus and joins the $9^{\text {th }}$ band at vein $\mathrm{CuA}_{2}$ or just below it in cell $\mathrm{CuA}_{2}$, the $9^{\text {th }}$ band curved inward in cell $\mathrm{R}_{4}$, the $10^{\text {th }}$ band independent, extending from the apex to vein $\mathrm{CuA}_{2}$ or just below it in cell $\mathrm{CuA}_{2}$; the veins $\mathrm{CuA}_{1}$ to $\mathrm{R}_{4+5}$ are black after meeting the $6^{\text {th }}$ and $7^{\text {th }}$ bands and then divide the whitishhyaline areas between the $6^{\text {th }}$ to $10^{\text {th }}$ bands into spots. Forewing underside: colour and markings as upperside, but the hyaline areas are glossier. Hindwing narrow triangulate in general, costa very oblique, vein $\mathrm{M}_{3}$ extends into a sword-like tail, termen slightly dented at the end of veins, the end of cells $\mathrm{CuA}_{1}$ to $\mathrm{M}_{1}$ scalloped. Hindwing upperside: white with long white hair covering the inner $1 / 3$; tornal margin without any black, a large brown androconial patch near the humeral, a black sub-basal band extends from the costal along the lower cellular vein and ends at the base of vein $\mathrm{CuA}_{2}$, while the remaining bands visible from underside, two obliquely neighbouring yellow tornal spots encircled by black lines, with a small greyish blue spot below; the discal bands completely absent but visible from the underside; the submarginal black band coupled and interrupted by veins $\mathrm{M}_{1}$ and Rs, reaching cell $R_{5}$ or $M_{1}$, with the inner bands fainter; the terminal band single, also interrupted by veins $M_{1}$ and Rs, reaching cell $\mathrm{R}_{5}$ or $\mathrm{R}_{1}$; all black bands, except the sub-basal one, join in the black area at the end of cells $\mathrm{CuA}_{1}$ to $\mathrm{M}_{2}$, with a greyish-blue lunule in each cell; tail black with white tip. Hindwing underside: colour and markings similar to upperside but with a pale yellow hue, all black bands and markings better defined, especially the basal, sub-basal, and discal bands, two discal black lines twisting into an " 8 "-shaped pattern, with both rings white or just a rather faint yellow tinge in the upper ring, the edge of the lower ring extends along veins $\mathrm{CuA}_{1}$ to $\mathrm{M}_{1}$; a square creamy white spot above each greyish-blue lunule in the tornal area, the yellow spots at the tornus reduced and crowned by fine white lines.

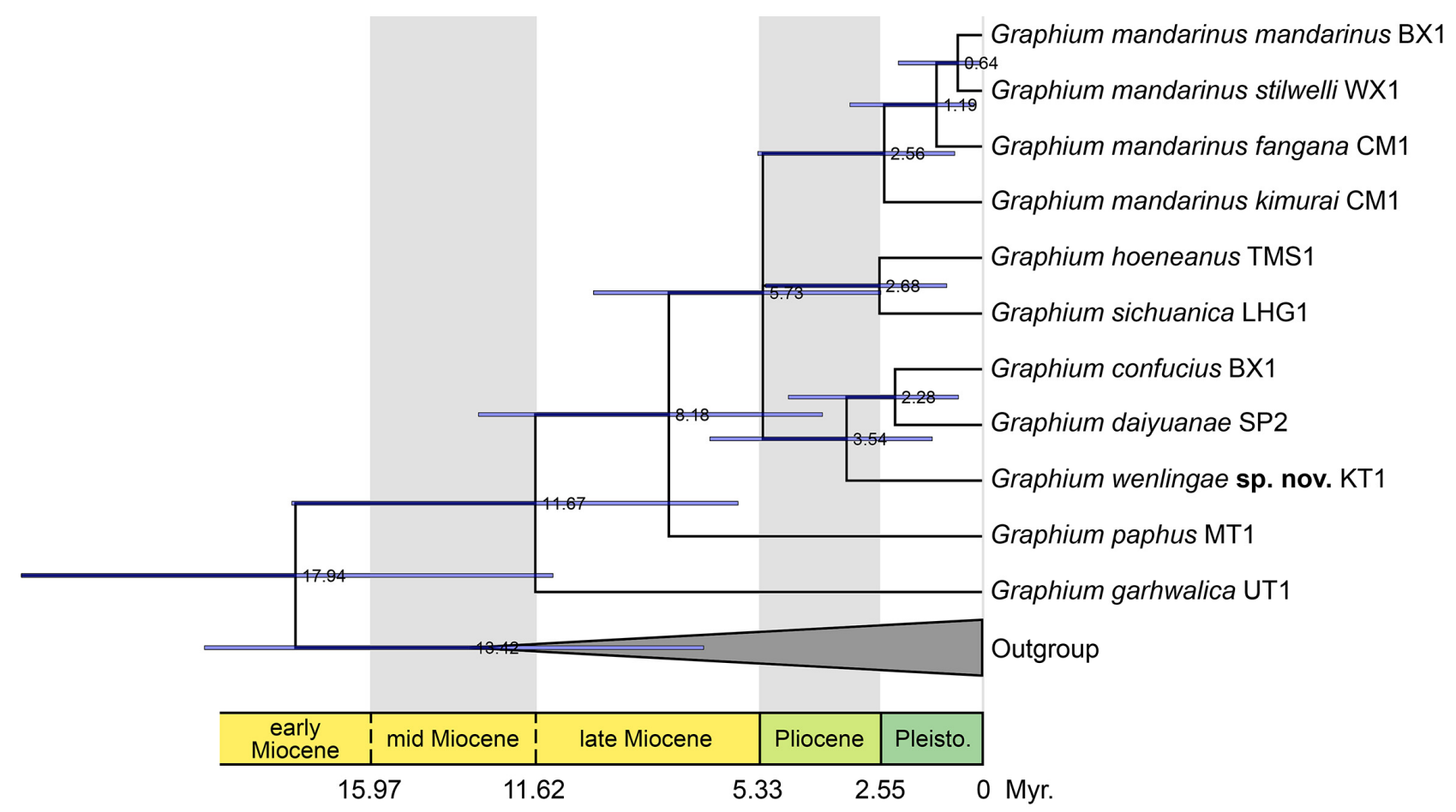

FIGURE 2. Bayesian molecular dating for species and subspecies in the Graphium (Pazala) mandarinus group, with outgroups collapsed. Values at nodes indicate the median divergence times, purple bars show 95\% CI. Pleisto. = Pleistocene. 
Female: Only two females were available. Forewing lengths of both specimens $34.0 \mathrm{~mm}$. General appearance similar to male but larger and even paler. The $4^{\text {th }}$ black band on the forewing not reduced.

Male genitalia (Figure 4): Two males were dissected, and found to be largely similar except for variation in the teeth of the medial harpe. Moderately sclerotised. Ring wavy in the upper half; saccus small; distance between the base of socii $0.40 \mathrm{~mm}(n=2)$. Valve oval in general, the dorsal terminal harpe with mostly straight edge and elongated acute tip; the edge of dorsal subterminal harpe almost touching the base of the tip of the dorsal terminal harpe; the medial harpe mostly straight, the dorsal projection bayonet-shaped with indented tip; a variable number of small teeth (1-2) occur in the middle of the medial harpe.

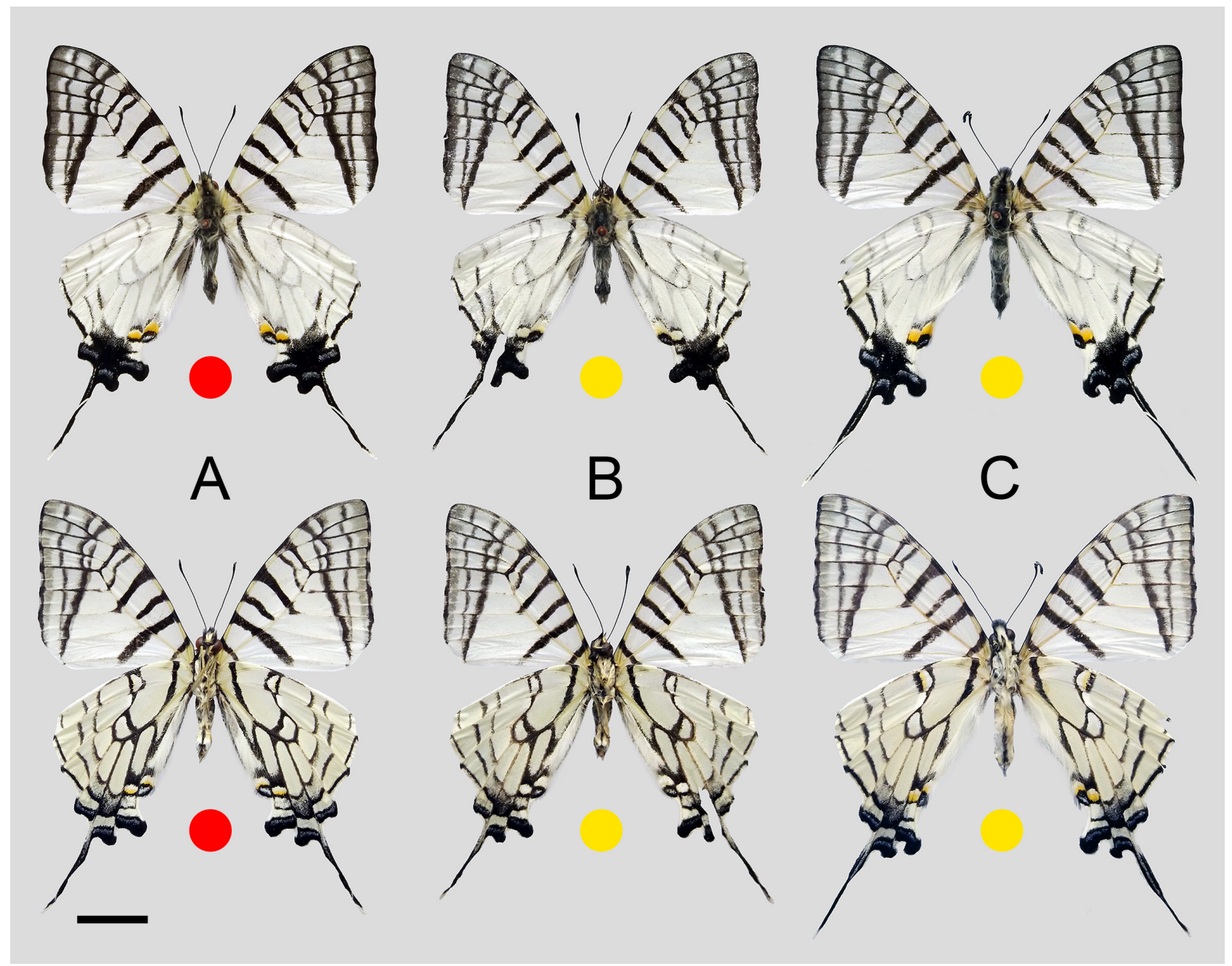

FIGURE 3. Graphium (Pazala) wenlingae Hu, Cotton \& Monastyrskii sp. nov.; red dot: holotype, yellow dots: paratypes; upperside on the first row, underside on the second row; A-B: 今̄, Ngoc Linh, Kon Tum, C. Vietnam; C: + , Tay Giang, Quang Nam, C. Vietnam; scale bar $=10 \mathrm{~mm}$.

Female genitalia (Figure 5): Only one female was available for dissection. Lamella postvaginalis distinctly rounded; lamella antevaginalis broad in the ventral plane, lined with moderately sclerotised longitudinal striae; ostial lobe heavily sclerotised, broad at the base and gradually narrowed into a sharp tip in lateral view, while the posterior margin is deeply concave with a pair of acute spurs in ventral view.

Differential Diagnosis: The new species resembles G. (P.) daiyuanae Hu, Zhang \& Cotton, 2018, G. (P.) mandarinus kimurai Murayama, 1982, G. (P.) mandarinus fangana (K. Okano, 1986), and G. (P.) mandarinus stilwelli Cotton \& $\mathrm{Hu}, 2018$ (Figure 6), but can be distinguished by careful examination of the following characters: 1) size smaller than daiyuanae and mandarinus stilwelli, similar to that of mandarinus kimurai and mandarinus fangana; 2) forewing termen not oblique outwardly from apex to tornus as in daiyuanae and female mandarinus kimurai and mandarinus fangana (a); 3) upperside hindwing rather paler, the basal, lower half of sub- 
basal, and discal bands completely absent in both sexes (while commonly present in other taxa) (b); 4) both rings of the discal bands on the hindwing underside mostly white, except a very thin line of creamy yellow in the upper ring (c) (the upper ring typically yellow in other taxa); 5) the interspaces between coupled submarginal bands at cells $\mathrm{M}_{3}$ and $\mathrm{M}_{2}$ more irrigated with whitish scales than in other taxa (d).

TABLE 2. Monophylizer assessment of species and subspecies in the Graphium (Pazala) mandarinus group.

\begin{tabular}{lll}
\hline Taxon & Assessment & Tanglees \\
\hline G. $($ P.) garhwalica & monophyletic & - \\
$G .(P$.$) paphus$ & monophyletic & - \\
G. $($ P.) sichuanica & monophyletic & - \\
$G .(P$.$) hoeneanus$ & monophyletic & - \\
$G .(P$.$) wenlingae sp. nov.$ & monophyletic & - \\
$G .(P$.$) daiyuanae$ & monophyletic & - \\
$G .(P$.$) confucius$ & monophyletic & - \\
$G .(P$.$) mandarinus$ & monophyletic & - \\
ssp. kimurai & monophyletic & - \\
ssp. fangana & monophyletic & - \\
ssp. stilwelli & paraphyletic & ssp. mandarinus, ssp.fangana \\
ssp. mandarinus & monophyletic & - \\
\hline
\end{tabular}

TABLE 3. The Kimura 2-parameter distances (shown in percentages) between taxa in Graphium (Pazala) mandarinus group, including $G$. (P.) wenlingae Hu, Cotton \& Monastyrskii sp. nov.

\begin{tabular}{|c|c|c|c|c|c|c|c|c|c|c|c|}
\hline Taxon & 1 & 2 & 3 & 4 & 5 & 6 & 7 & $8 \mathrm{a}$ & $8 b$ & $8 \mathrm{c}$ & $8 \mathrm{~d}$ \\
\hline \multicolumn{12}{|l|}{ 1. garhwalica } \\
\hline 2. paphus & 5.42 & & & & & & & & & & \\
\hline 3. sichuanica & 4.85 & 5.07 & & & & & & & & & \\
\hline 4. hoeneanus & 5.08 & 4.81 & 2.04 & & & & & & & & \\
\hline 5. wenlingae sp. nov. & 4.81 & 4.83 & 2.79 & 3.47 & & & & & & & \\
\hline 6. daiyuanae & 4.54 & 5.32 & 3.98 & 3.42 & 2.38 & & & & & & \\
\hline 7. confucius & 5.27 & 5.12 & 4.16 & 4.09 & 2.24 & 1.71 & & & & & \\
\hline 8a. mandarinus kimurai & 6.20 & 5.72 & 4.01 & 4.17 & 3.78 & 3.88 & 3.41 & & & & \\
\hline 8b. mandarinus fangana & 5.76 & 5.96 & 3.39 & 4.11 & 3.03 & 3.46 & 2.67 & 1.64 & & & \\
\hline 8c. mandarinus stilwelli & 5.93 & 6.13 & 3.55 & 4.28 & 3.19 & 3.62 & 3.12 & 1.48 & 0.46 & & \\
\hline 8d. mandarinus mandarinus & 6.48 & 6.33 & 4.01 & 4.43 & 3.38 & 3.22 & 2.99 & 1.67 & 0.95 & 0.49 & \\
\hline
\end{tabular}

In male genitalia, the tip of dorsal terminal harpe acute and elongated (short in mandarinus and daiyuanae), dorsal subterminal harpe large, joining dorsal terminal harpe and forming a triangle, dorsal projection bayonetshaped (Figure 4), distance between the base of socii $0.40 \mathrm{~mm}$. In female genitalia the ostial lobe forming a large up-curving spur in lateral view, the posterior margin deeply concave with a pair of acute spurs in ventral view (Figure 5).

Type Material: Holotype: VIETNAM: ${ }^{\lambda}$, Ngoc Linh National Park $\left(15^{\circ} 07.432^{\prime}\right.$ N, $107^{\circ} 59.915^{\prime}$ E; 2,416 m), Kon Tum Province, 2018-IV, D. N. Vang leg. [KIZ, 0101805].

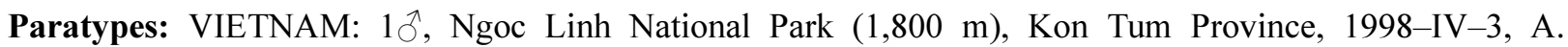

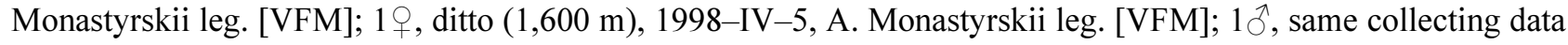
as holotype [SJH]; 1 , , Tay Giang (1,300 m), Quang Nam Province, 2017-IV, L. T. Le leg. [KIZ, 0101806].

The holotype and one paratype were deposited in Kunming Institute of Zoology (KIZ), Chinese Academy of Sciences (Li et al. 2015). 
Distribution: The new species is currently known only from Kon Tum plateau of Truong Son (Annamite) Range in C. Vietnam (Quang Nam and Kon Tum Provinces). We can also expect to discover this species in adjacent Gia Lai Province (e.g. Kon Ka Kinh National Park) and in Lam Dong Province (e.g. Bi Doup Nui Ba and Chu Yang Sin National Parks).

Phenology: Likely univoltine. All specimens in this study were collected in April.

Host plant: Unknown, presumably a plant species belonging to family Lauraceae representatives of which (e.g. genera Neolitsea, Machilus, Cinnamomum, and Persea) are host plants of such relatives as Graphium (Pazala) eurous and G. (P.) mullah (Igarashi \& Fukuda 2000).

Derivatio nominis: The specific name of this elusive new taxon was dedicated to Dr. Wen-Ling Wang, a very close friend of the first author. The species name is to be treated as a noun in apposition.

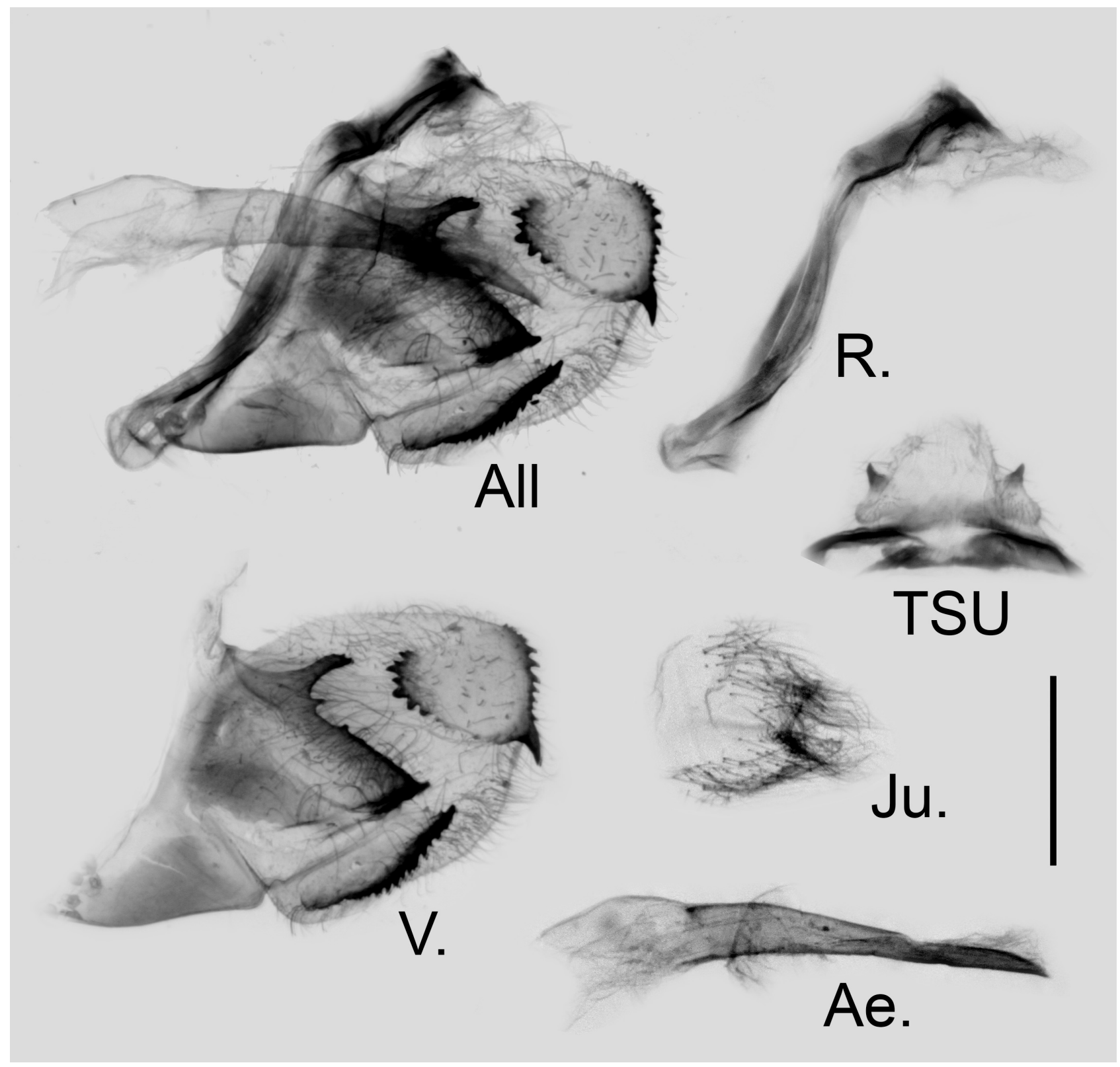

FIGURE 4. Male genitalia of Graphium (Pazala) wenlingae Hu, Cotton \& Monastyrskii sp. nov. from Ngoc Linh, Kon Tum, C. Vietnam; scale bar $=1.0 \mathrm{~mm}$. All: genitalia as a whole, R.: lateral view of ring, TSU: dorsal view of tegumen, socii, and uncus, V. right valve, Ae.: lateral view of aedeagus, Ju.: ventral view of juxta. 


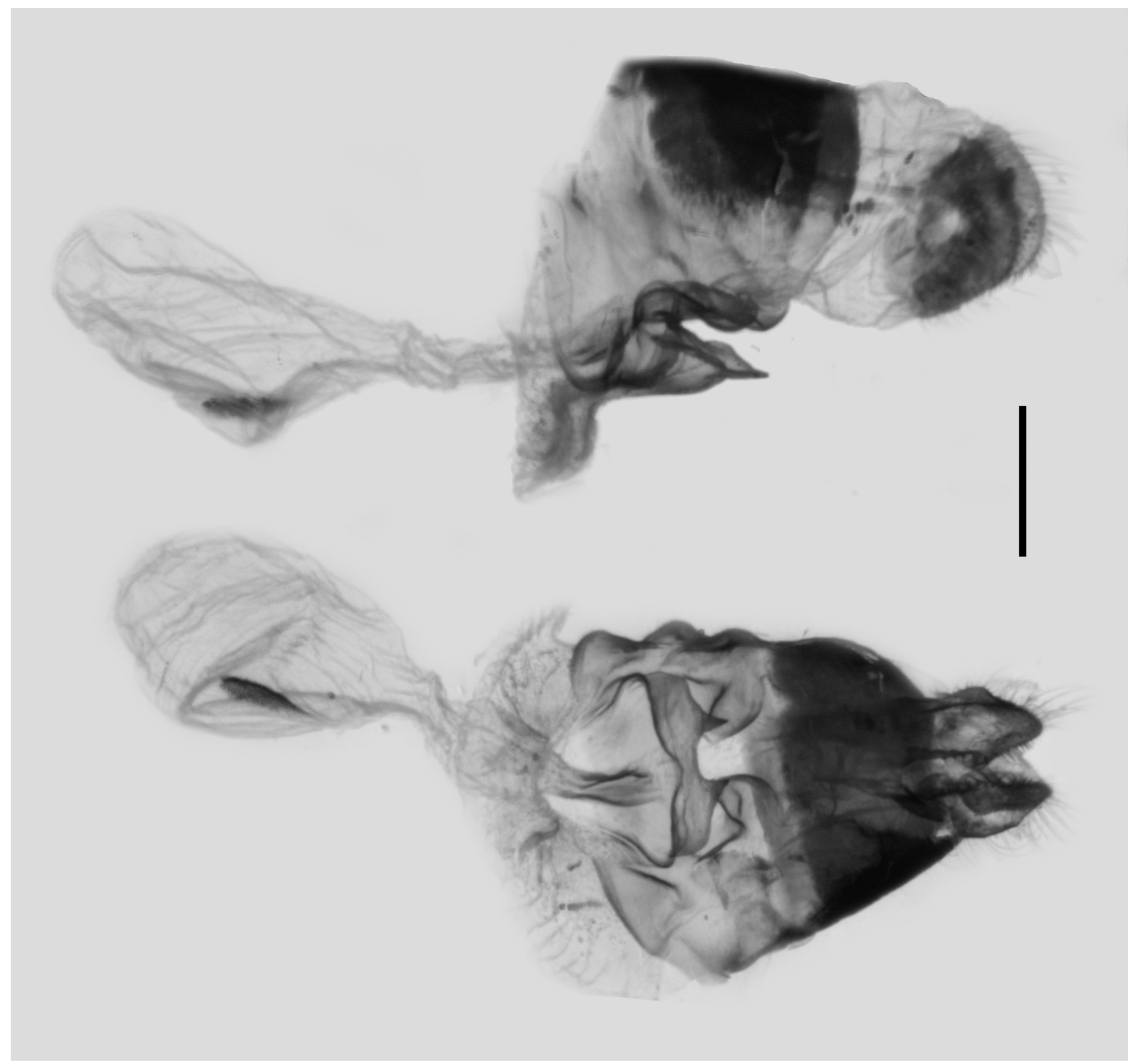

FIGURE 5. Female genitalia of Graphium (Pazala) wenlingae Hu, Cotton \& Monastyrskii sp. nov. from Tay Giang, Quang Nam, C. Vietnam; lateral view above, ventral view below; scale bar $=1.0 \mathrm{~mm}$.

\section{Key to taxa of the $G(P$.$) mandarinus group based on wing pattern$}

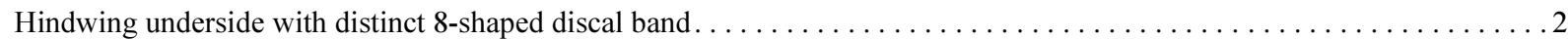

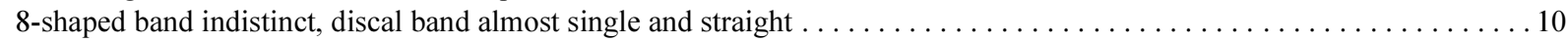

Forewing apex produced, usually larger in size, with prominent black bands and bright yellow markings ....... confucius

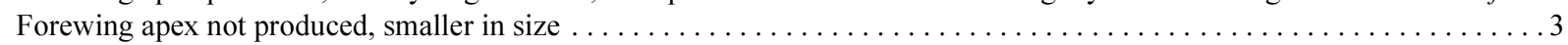

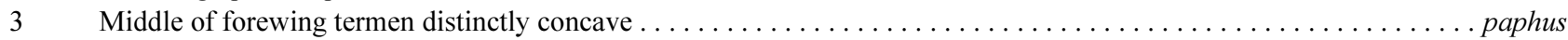

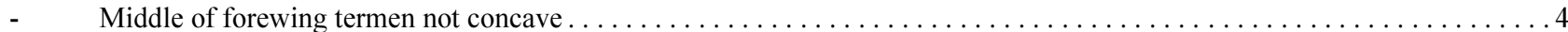

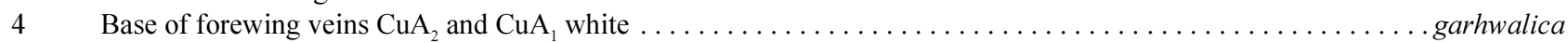

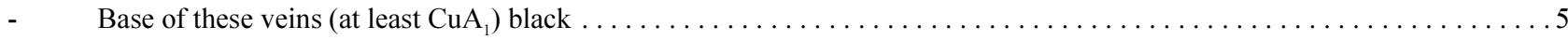

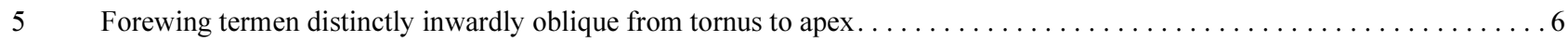

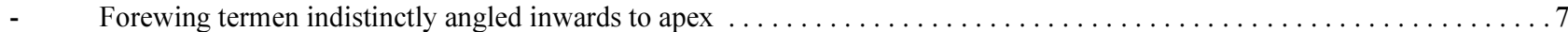

6 Basal band on hindwing upperside usually complete, yellow markings on the underside brighter ...........daiyuanae

- $\quad$ Basal band on hindwing upperside incomplete, yellow markings on the underside rather pale. .......... wenlingae sp. nov.

$7 \quad$ Larger and darker, basal band on hindwing upperside complete, discal band on hindwing upperside usually present ........

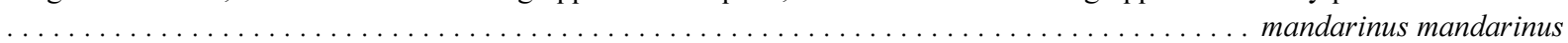


Medium sized, discal band on hindwing upperside incomplete, only with a trace above the discocell . . . mandarinus stilwelli

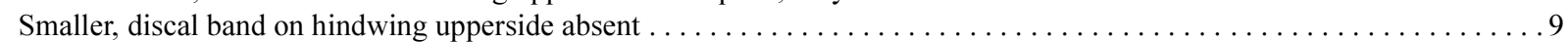

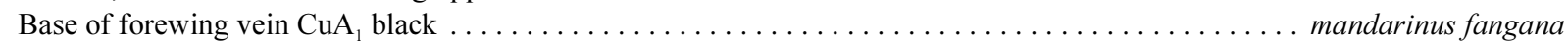

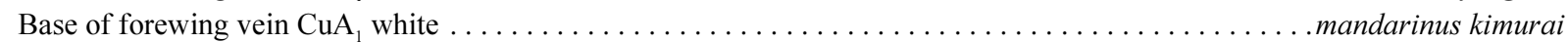

10 Smaller and darker, $9^{\text {th }}$ forewing band reaches the tornus, hindwing subterminal band continuous. . . . . . . . sichuanica - $\quad$ Larger and paler, $9^{\text {th }}$ forewing band not reaching the tornus, hindwing subterminal band interrupted. ........ hoeneanus

\section{Discussion}

The discovery of G. (P.) wenlingae sp. nov. increases the total number of members of the mandarinus group to eight species. Three of them are distributed in northern and central parts of Vietnam (Figure 7); however, the current work is not the first publication to record their distribution in the country. Monastyrskii \& Devyatkin (2015) had already collated records of Graphium mandarinus (Oberthür, 1879) from N. Vietnam (Lao Cai and Ha Giang Provinces) and C. Vietnam (Kon Tum Province). Based on our previous work (Hu et al., 2018) and the current study, three separate species were previously recorded in Vietnam under the name 'mandarinus'. These three species are G. (P.) confucius from Lao Cai and Ha Giang Provinces, G. (P.) daiyuanae from Lao Cai Province and $G$. (P.) wenlingae sp. nov. from Kon Tum and Quang Nam Provinces. The high species richness of the mandarinus group in Indochina is not an unexpected fact. A number of other representatives of Sino-Himalayan butterfly fauna have previously been found in Vietnam (Monastyrskii 2010). The Truong Son (Annamite) Range, extending for nearly $1,200 \mathrm{~km}$ from north to south along the Vietnamese border with Laos and Cambodia is a rather poorly studied area of butterfly endemism (Monastyrskii \& Holloway 2013). For Pazala, a complex group, the species/ subspecies richness, geographic distribution and endemism in this area would be intriguing topics to study further. This area represents a new range extension for this once-believed Palaearctic subgenus of Graphium. Answering these aspects would greatly complement our understanding of Pazala, and eventually benefit the modern taxonomy of Graphium, as recommended by Smith (2005).

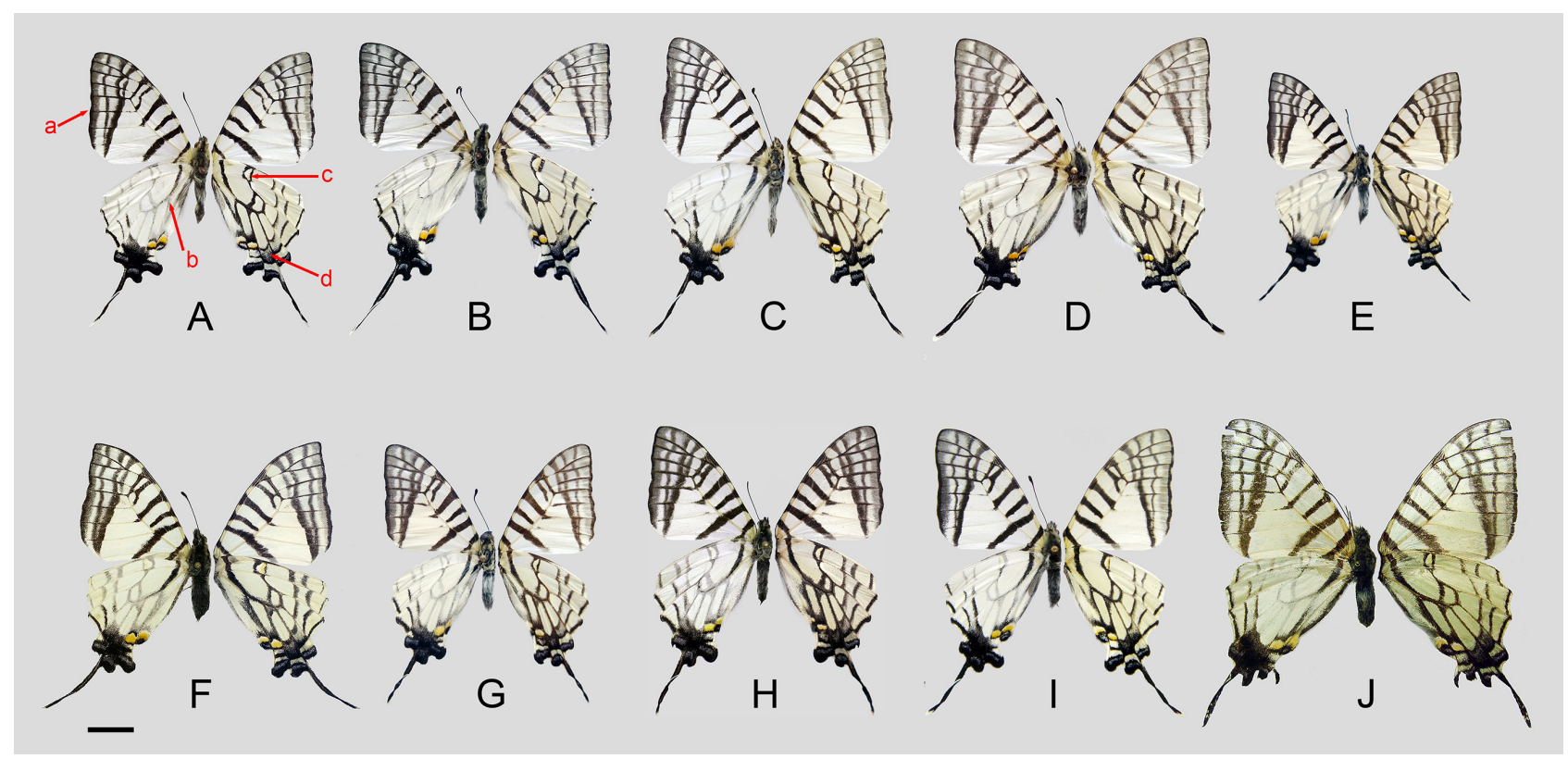

FIGURE 6. Differential diagnoses of Graphium (Pazala) wenlingae Hu, Cotton \& Monastyrskii sp. nov. (A: $\widehat{O}$, B: $\odot$ ) and similar taxa, upperside on the left half, underside on the right half; C: G. (P.) daiyuanae Hu, Zhang \& Cotton, 2018, Õ; D: ditto,

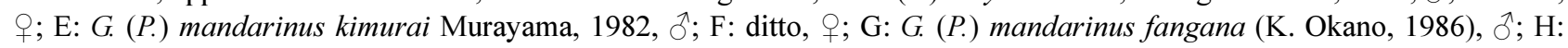

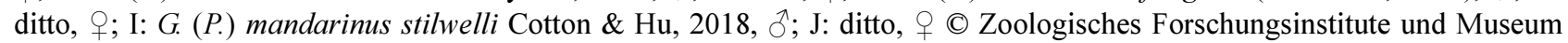
Alexander Koenig (ZFMK), Bonn, Germany; scale bar $=10 \mathrm{~mm}$.

Currently G. (P.) wenlingae sp. nov. is only known from the restricted area of the Kon Tum plateau in the central part of the Truong Son Range. This is isolated by a central section of relatively low hills from the mountains of northern Truong Son. The gap between the ranges of $G$. (P.) wenlingae sp. nov. and both $G$. (P.) daiyuanae and $G$. 
(P.) confucius, where no taxa in the mandarinus group have yet been recorded, is about $950 \mathrm{~km}$. There may potentially be habitat for one or more of these mandarinus group species in this region.

The Truong Son Range consists of very old mountains formed in the Paleozoic and Mesozoic epochs (Averyanov et al. 2003), long before the mid Pliocene to early Pleistocene when the divergence of G. (P.) wenlingae sp. nov. occurred, according to our molecular dating analysis (Figure 2). During this period, with the climate cooling down in an oscillating pattern (Zachos et al. 2001) and eventually reaching the last glacial maximum (LGM) globally, the low-altitude river valleys gradually played the role of refugial shelters for animals in the cold periods of climate oscillation (Stewart \& Lister 2001; Keppel et al. 2012). After each cold period, with the increase in temperature when the climate entered the next warm period, plausibly many species would have again retreated to higher altitudes into cooler habitats. Such cyclical repeated movements driven by climate oscillation are widely accepted as a vicariance driver in Indochina, especially along the Truong Son Range (Woodruff 2010; Kong et al. 2017). Our molecular dating analysis showed that $G$. (P.) wenlingae sp. nov. split before $G$. $(P$.) daiyuanae $+G$. $(P$.) confucius, which can probably be attributed to the quicker warming up in the southern part of Vietnam compared to the North in each oscillating cycle.

A similar hypothesis may also be applied to the $G$. (P.) sichuanica $+G$. (P.) hoeneanus clade and the entire $G$. (P.) mandarinus clade, which occupies the eastern margin of the Hengduan Mountains to various hills in S. to S.E. China, and the southern margin of the Hengduan Mountains to the Shan Highlands (Figure 7), where climate oscillation in the Pliocene to Pleistocene also prevailed (Zachos et al. 2001). The trichotomy in our molecular dating analysis, the low support values for those nodes, as well as very similar external and genitalic morphology all suggested a fast divergence between lineages.

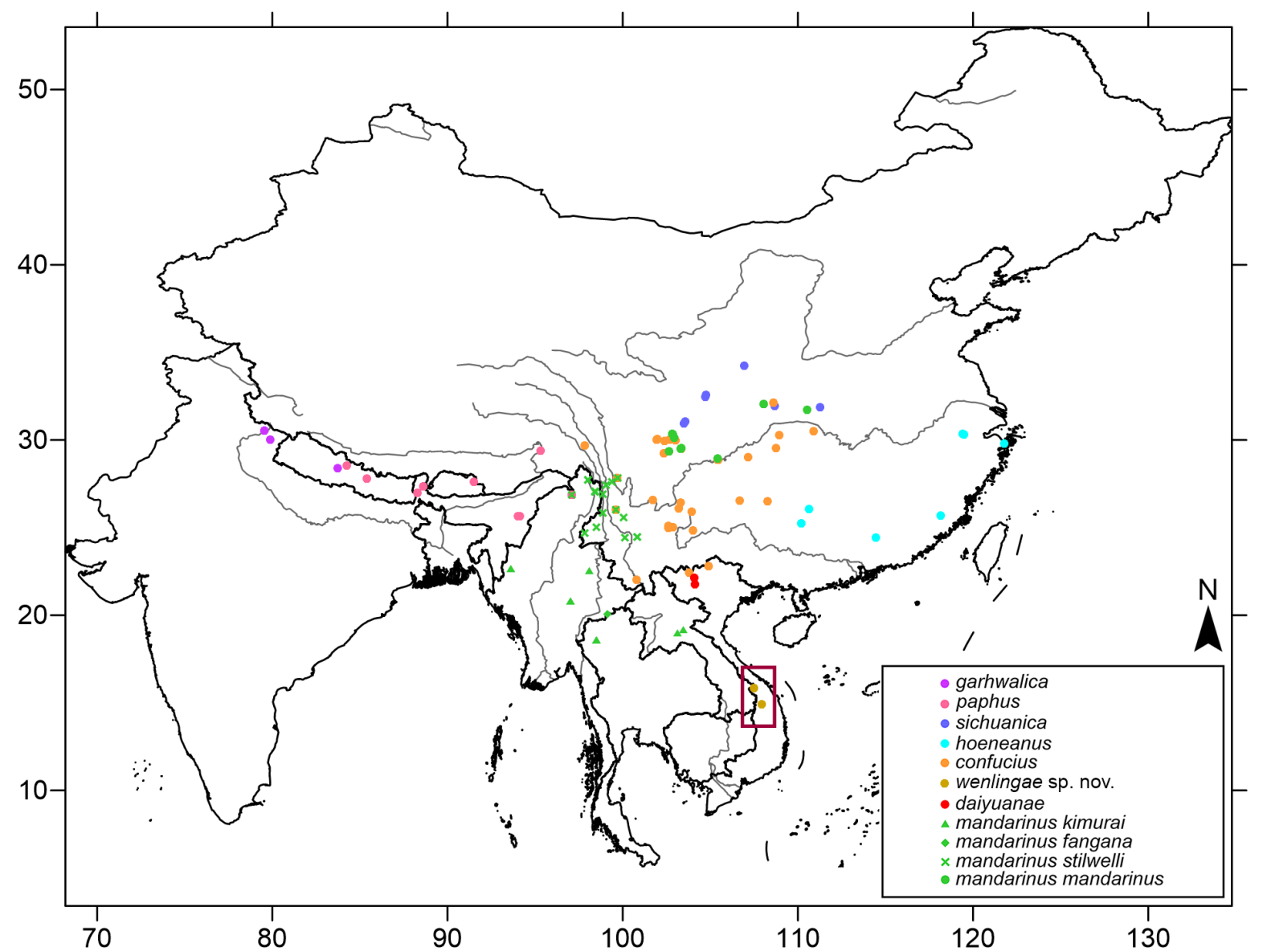

FIGURE 7. Distribution map of the Graphium (Pazala) mandarinus group, with the distribution of $G$. (P.) wenlingae sp. nov. highlighted in a red box. 


\section{Acknowledgements}

We thank R. I. Vane-Wright, T. Racheli, and an anonymous reviewer for providing very useful comments on the manuscript. This study was funded by the NSFC Programme of China (41761011) and the Biodiversity Conservation Programme of the Ministry of Ecology and Environment, China (China-BON Butterflies) (SDZXWJZ01013).

\section{References}

Averyanov, L.V., Phan, K.L., Nguyen, T.H. \& Harder, D.K. (2003) Phytogeographic review of Vietnam and adjacent areas of eastern Indochina. Komarovia, 3, 1-83.

Ayres, D.L., Darling, A., Zwickl, D.J., Beerli, P., Holder, M.T., Lewis, P.O., Huelsenbeck, J.P., Ronquist, F., Swofford, D.L., Cummings, M.P., Rambaut, A. \& Suchard, M.A. (2012) BEAGLE: an application programming interface and highperformance computing library for statistical phylogenetics. Systematic Biology, 61, 170-173. https://doi.org/10.1093/sysbio/syr100

Bertheau, C., Schuler, H., Krumböck, S., Arthofer, W. \& Stauffer, C. (2011) Hit or miss in phylogenetic analyses: the case of the cryptic NUMTs. Molecular Ecology Resources, 11, 1056-1059. https://doi.org/10.1111/j.1755-0998.2011.03050.x

Condamine, F.L., Sperling, F.A.H., Wahlberg, N., Rasplus, J.-Y. \& Kergoat, G.J. (2012) What causes latitudinal gradients in species diversity? Evolutionary processes and ecological constraints on swallowtail biodiversity. Ecology Letters, 15, 267277. https://doi.org/10.1111/j.1461-0248.2011.01737.x

Folmer, O., Black, M.B., Hoch, W., Lutz, R.A. \& Vrijehock, R.C. (1994) DNA primers for amplification of mitochondrial cytochrome c oxidase subunit I from diverse metazoan invertebrates. Molecular Marine Biology and Biotechnology, 3, 294-299.

Hall, T.A. (1999) BioEdit: a user-friendly biological sequence alignment editor and analysis program for Windows 95/98/NT. Nuclear Acids Symposium Series, 41, 95-98.

Hu, S.J., Cotton, A.M., Condamine, F.L., Duan, K., Wang, R.J., Hsu, Y.F., Zhang, X. \& Cao, J. (2018) Revision of Pazala Moore, 1888: the Graphium (Pazala) mandarinus (Oberthür, 1879) group, with treatments of known taxa and descriptions of new species and new subspecies (Lepidoptera: Papilionidae). Zootaxa, 4441, 401-446. https://doi.org/10.11646/zootaxa.4441.3.1

Huelsenbeck, J.P., Larget, B. \& Alfaro, M.E. (2004) Bayesian phylogenetic model selection using reversible jump Markov Chain Monte Carlo. Molecular Biology and Evolution, 21, 1123-1133. https://doi.org/10.1093/molbev/msh123

Igarashi, S. \& Fukuda, H. (2000) The Life Histories of Asian Butterflies. II . Univ. Press, Tokyo, 711 pp..

Keppel, G., Van Niel, K.P., Wardell-Johnson, G.W., Yates, C.J., Byrne, M., Mucina, L., Schut, A.G.T., Hopper, S.D. \& Franklin, S.E. (2012) Refugia: identifying and understanding safe havens for biodiversity under climate change. Global Ecology and Biogeography, 21, 393-404. https://doi.org/10.1111/j.1466-8238.2011.00686.x

Kimura, M. (1980) A simple method for estimating evolutionary rates of base substitutions through comparative studies of nucleotide sequences. Journal of Molecular Evolution, 16, 111-120. https://doi.org/10.1007/BF01731581

Koiwaya, S. (1993) Description of three new genera, eleven new species and seven new subspecies of butterflies from China. Studies of Chinese Butterflies, 2, 43-111, pls. 9-27. [in Japanese with English descriptions]

Kong, H.L., Condamine, F.L., Harris, A.J., Chen, J.L., Pan, B., Möller, M., Hoang, V.S. \& Kang, M. (2017) Both temperature fluctuations and East Asian monsoons have driven plant diversification in the karst ecosystems from southern China. Molecular Ecology, 26, 6414-6429. https://doi.org/10.1111/mec.14367

Lanfear, R., Frandsen, P.B., Wright, A.M., Senfeld, T. \& Calcott, B. (2017) PartitionFinder 2: new methods for selecting partitioned models of evolution for molecular and morphological phylogenetic analyses. Molecular Biology and Evolution, 34, 772-773. https://doi.org/10.1093/molbev/msw260

Lepage, T., Bryant, D., Philippe, H. \& Lartillot, N. (2007) A general comparison of relaxed molecular clock models. Molecular Biology and Evolution, 24, 2669-2680. https://doi.org/10.1093/molbev/msm193

Li, K.Q., Wang, Y.Z., Dong, D.Z. \& Zhang, L.K. (2015) Catalog of insect type specimens preserved at the Kunming Institute of Zoology, Chinese Academy of Science with corrections of some specimens. Zoological Research, 36, 263-284. https://doi.org/10.13918/j.issn.2095-8137.2015.5.263

Miller, M.A., Schwartz, T., Pickett, B.E., He, S., Klem, E.B., Scheuermann, R.H., Passarotti, M., Kaufman, S. \& O'Leary, M.A. 
(2015) A RESTful API for access to phylogenetic tools via the CIPRES science gateway. Evolutionary Bioinformatics Online, 11, 43-48.

https://doi.org/10.4137/EBO.S21501

Minh, B.Q., Nguyen, M.A.T. \& von Haeseler, A. (2013) Ultrafast approximation for phylogenetic bootstrap. Molecular Biology and Evolution, 30, 1188-1195.

https://doi.org/10.1093/molbev/mst024

Monastyrskii, A.L. (2007) Butterflies of Vietnam. Papilionidae. Vol. 2. Dolphin Media, 158 pp.

Monastyrskii, A.L. (2010) On the origin of the recent fauna of butterflies (Lepidoptera, Rhopalocera) of Vietnam. Entomology Review, 90, 39-58. https://doi.org/10.1134/S0013873810010045

Monastyrskii, A.L. \& Devyatkin, A.L. (2000) New taxa and new records of butterflies from Vietnam (Lepidoptera, Rhopalocera). Atalanta, 31 (3/4), 471-492.

Monastyrskii, A.L. \& Devyatkin, A.L. (2003) Butterflies of Vietnam (an Illustrated checklist). Thong Nhat Printing House, 56 pp., 14 pls.

Monastyrskii, A.L. \& Holloway, J.D. (2013) Chapter 5. The Biogeography of the Butterfly Fauna of Vietnam With a Focus on the Endemic Species (Lepidoptera). In: Sivia-Opps, M. (Ed.), Current Progress in Biological Research. IntechOpen, Rijeka, pp. 95-123.

Monastyrskii, A.L. \& Devyatkin, A.L. (2015) Butterflies of Vietnam (An Illustrated Checklist). $2^{\text {nd }}$ Edition. Planorama Media Co., Ltd., Hanoi, 59 pp.

Mutanen, M., Kivelä, S.M., Vos, R.A., Doorenweerd, C., Ratnasingham, S., Hausmann, A., Huemer, P., Dincă, V., van Nieukerken, E.J., Lopez-Vaamonde, C., Vila, R., Aarvik, L., Decaëns, T., Efetov, K.A., Hebert, P.D.N., Johnsen, A., Karsholt O., Pentinsaari, M., Rougerie, R., Segerer, A., Tarmann, G., Zahiri, R. \& Godfray, H.C.J. (2016) Species-level para- and polyphyly in DNA barcode gene trees: strong operational bias in European Lepidoptera. Systematic Biology, 65, 1024-1040. https://doi.org/10.1093/sysbio/syw044

Nguyen, L.T., Schmidt, H.A., von Haeseler, A. \& Minh, B.Q. (2015) IQ-TREE: a fast and effective stochastic algorithm for estimating maximum-likelihood phylogenies. Molecular Biology and Evolution, 32, 268-274. https://doi.org/10.1093/molbev/msu300

O’Neill, S.L., Giordano, R., Colbert, A.M.E., Karr, T.L. \& Robertson, H.M. (1992) 16S rRNA phylogenetic analysis of the bacterial endosymbionts associated with cytoplasmic incompatibility in insects. Proceedings of the National Academy of Sciences of the United States of America, 89, 2699-2702. https://doi.org/10.1073/pnas.89.7.2699

Racheli, T. \& Cotton, A.M. (2009) Guide to the Butterflies of the Palearctic Region. Papilionidae. Part I. Milano, Omnes Artes, 70 pp.

Rehm, P., Borner, J., Meusemann, K., von Reumont, B.M., Simon, S., Hadrys, H., Misof, B. \& Burmester, T. (2011) Dating the arthropod tree based on large-scale transcriptome data. Molecular Phylogenetics and Evolution, 61, 880-887. https://doi.org/10.1016/j.ympev.2011.09.003

Ronquist, F., Teslenko, M., Van Der Mark, P., Ayres, D.L., Darling, A., Höhna, S., Larget, B., Liu, L., Suchard, M.A. \& Huelsenbeck, J.P. (2012) MrBayes 3.2: efficient Bayesian phylogenetic inference and model choice across a large model space. Systematic Biology, 61, 539-542. https://doi.org/10.1093/sysbio/sys029

Schenk, J.J. (2016) Consequences of secondary calibrations on divergence time estimates. PLoS ONE, 11, e0148228. https://doi.org/10.1371/journal.pone.0148228

Smith, C.R. (2005) Why we are studying Oriental Graphium (Lepidoptera: Papilionidae) at the Natural History Museum, London. In: Yata, O. (Ed.), A Report on Insect Inventory Project in Tropic Asia (TAIIV) "Network construction for the establishment of insect inventory in Tropic Asia (TAIIV)". Kyushu University, Fukuoka, pp. 49-56.

Smith, C.R. \& Vane-Wright, R.I. (2001) A review of the Afrotropical species of the genus Graphium (Lepidoptera: Rhopalocera: Papilionidae). Bulletin of the British Museum (Natural History) Entomology, 70, 503-719.

Song, H., Buhay, J.E., Whiting, M.F. \& Crandall, K.A. (2008) Many species in one: DNA barcoding overestimates the number of species when nuclear mitochondrial pseudogenes are coamplified. Proceedings of the National Academy of Sciences of the United States of America, 105, 13486-13491. https://doi.org/10.1073/pnas.0803076105

Stewart, J.R. \& Lister, A.M. (2001) Cryptic northern refugia and the origins of the modern biota. TRENDS in Ecology \& Evolution, 16, 608-613. https://doi.org/10.1016/s0169-5347(01)02338-2

Tamura, K., Stecher, G., Peterson, D., Filipski, A. \& Kumar, S. (2013) MEGA6: Molecular evolutionary genetics analysis version 6.0. Molecular Biology and Evolution, 30, 2725-2729. https://doi.org/10.1093/molbev/mst197

Thompson, J.D., Higgins, D.G. \& Gibson, T.J. (1994) CLUSTAL W: improving the sensitivity of progressive multiple sequence alignment through sequence weighting, position-specific gap penalties and weight matrix choice. Nuclear Acids Research, 22, 4673-4680. 
https://doi.org/10.1093/nar/22.22.4673

Thorne, J.L. \& Kishino, H. (2002) Divergence time and evolutionary rate estimation with multilocus data. Systematic Biology, 51, 689-702. https://doi.org/10.1080/10635150290102456

Thorne, J.L., Kishino, H. \& Painter, I.S. (1998) Estimating the rate of evolution of the rate of molecular evolution. Molecular Biology and Evolution, 15, 1647-1657. https://doi.org/10.1093/oxfordjournals.molbev.a025892

Woodruff, D.S. (2010) Biogeography and conservation in Southeast Asia: how 2.7 million years of repeated environmental fluctuations affect today's patterns and the future of the remaining refugial-phase biodiversity. Biodiversity Conservation, 19, 919-941. https://doi.org/10.1007/s10531-010-9783-3

Zachos, J., Pagani, M., Sloan, L., Thomas, E. \& Billups, K. (2001) Trends, rhythms, and aberrations in global climate 65 Ma to present. Science, 292, 686-693.

https://doi.org/10.1126/science.1059412 